\title{
O BRINCAR E A LINGUAGEM: UMA INTERFACE NECESSÁRIA À CLÍNICA PSICANALÍTICA
}

\author{
Iassana Scariot \\ Universidade Federal do Rio Grande do Sul - UFRGS - Brasil \\ Liliane Seide Froemming \\ Universidade Federal do Rio Grande do Sul - UFRGS - Brasil
}

\section{Resumo}

O presente trabalho tem como foco principal o brincar e a linguagem no espaço de atendimento clínico de crianças e sua importância para a constituição psíquica do sujeito. Para trabalhar a linguagem e o brincar na Psicanálise e verificar suas mútuas influências, utilizamos dois casos clínicos. Dividimos o trabalho em quatro tópicos: nascendo um "fala ser"; sopa de letrinhas: a linguagem na constituição; brincando a gente se entende; brincando com palavras. $\mathrm{O}$ brincar a linguagem são essenciais na construção de significantes na infância. Aos poucos a palavra se destaca do contexto imediato da necessidade de nomear e adquire caráter cada vez mais simbólico e representativo. Ao emprestar significantes a uma criança em atendimento clínico estamos inscrevendo nesta, nosso desejo que ela não sofra com seus problemas, mas sim, saiba conduzi-los e venha a se tornar um sujeito desejante. Esse trabalho é de grande relevância para uma escuta mais aguçada e um olhar mais sensível para a clínica psicanalítica da infância.

Palavras chave: brincar, linguagem, clínica psicanalítica.

“Certa palavra dorme na sombra

De um livro raro.

Como desencantá-la?

É a senha da vida

A senha do mundo.

Vou procurá-la.

[...]

Procuro sempre, e minha procura

Ficará sendo

Minha palavra. 
Carlos Drummond de Andrade, A Palavra

Mágica, em 'Discurso de Primavera'

\section{Nascendo um fala ser ${ }^{1}$}

Qual é o tempo de falar? Como isso acontece? Falar se aprende ou nascemos sabendo? Há como conviver sem falar? Há como brincar sem falar? E falar sem brincar? Tais questões nos convocam por acreditar que a linguagem é constituinte do psiquismo, e nos inspiram a escrever este texto, mas, de que linguagem estamos falando? Os casos de Willian e David são casos onde o campo da fala, da linguagem e do brincar se fazem presentes, de maneiras distintas e curiosas.

A constituição psíquica refere-se à dimensão do desenvolvimento responsável pela instalação da subjetividade. Nesta se apoiam os laços de afeto e de desejo dirigidos aos outros. No bebê, por exemplo, a instalação da subjetividade inicia desde cedo, até mesmo antes de seu nascimento, e também está presente no contato com as pessoas que dele se ocupam. Segundo Kupfer (2000), a mãe antecipará em seu bebê uma existência subjetiva que ainda não está lá, mas que virá a instalar-se justamente por que foi por ela, suposta. Dessa maneira, o fato desta mãe ou cuidador supor ali, um sujeito, permite a transformação das manifestações do bebê em pedidos a ela dirigidos, o que possibilita o estabelecimento da demanda entre a dupla.

Esse momento é decisivo na constituição do psiquismo do bebê, pois além de propiciar a satisfação, só pode ocorrer a partir da interpretação das ações do bebê e dentro do contexto do laço mãe-bebê. Essa comunicação entre mãe e bebê é silenciosa, segundo Winnicot (2006), uma canção sem palavras.

Essa comunicação dual através da voz e do olhar é o que por vezes ocorre na clínica com Willian $^{2}$, um paciente de seis anos. Ele já passou por exames, frequentou uma gama de profissionais com a queixa de que ele não fala, mas nada foi descoberto. Willian fala nas suas primeiras sessões palavras como: "socorro", "mamãe", "papai" e "tia". Deduzi a partir disso, que ele se referia a seus pais e a mim, quando me chamava de "tia", mas o que ele queria falar com o "socorro" refletido em seu brincar?

Para descobrir o que Willian quer, manifesto opções de atividades mostrando-lhe sua caixa de materiais. Ele pega alguns bonecos e inicia uma luta, e com sons os caracteriza, o que 
permite identificar que eles lutam. O boneco, por vezes, se torna uma extensão do corpo dele. Ao observar sua brincadeira, ele me convida a lutar, entregando-me uma boneca. Nos momentos em que falo na brincadeira, fazendo os personagens terem voz, Willian pausa e olha para mim atentamente. Dessa maneira, me encontrava inscrevendo palavras, ações, investindo nessa relação via transferência, como a relação mãe- bebê.

A partir deste contexto, Bergés e Balbo (1997) destacam que a voz e o olhar são os objetos com tamanha relevância, os quais marcam a presença e ausência, e assim fazem com que o corpo do bebê seja engajado na palavra. Jerusalinsky (2010) corrobora dizendo que a prosódia especial materna, o jeitinho de falar com o bebê,

transpõe para a ordem da letra o que até ali se encontrava no olhar. Olhar este que fica, então, arcaizado (enquanto marca residual) por obra do recalque originário (urverdrängung) operado por essa substituição. Assim a voz se transforma em letra pelo simples fato de que já não é ela mesma, em tanta coisa, mas signo de um objeto (o olhar) que ela passa a representar em outro nível. (pg. 48-49).

As pequenas ausências entre a mãe/cuidador e seu bebê refletirão todas as experiências de vida humana. Pesaro (2010) compartilha que a alternância entre momentos de presença e de ausência materna permite que a criança elabore um dispositivo subjetivo que dá lugar à simbolização da ausência. É a partir disso que a presença materna se torna não somente física, mas também simbólica.

Essa passagem me lembra o caso de David $^{3}$, quando pegávamos a caixa de material, íamos para a sala e eu me ausentava por um instante para guardar a chave. Ao voltar batia na porta e já a abrindo perguntava se podia entrar, ele dizia que não, então eu a fechava, e a abria novamente realizando a mesma pergunta e obtendo a mesma reposta. David intercalava a permissão de entrada, quando a porta estava fechada, com a recusa desta, quando eu abria a porta. Permanecíamos por algum momento nessa ação, de não entra - entra na sala.

O intervalo de tempo entre o entra e sai é semelhante ao Fort/Da. Nesse jogo, David tinha o tempo de falar para que eu o entendesse, já que sua fala era rápida e confusa, com palavras curtas e espaçadas. Há um intervalo entre o falar que pode entrar e o não pode, o intervalo da porta fechada.

Freud (1920/ 1996) descreve a brincadeira de seu neto de dezoito meses, na qual o menino arremessava seu carretel, fazendo-o desaparecer por entre as cortinas, emitindo, ao mesmo Barbarói, Santa Cruz do Sul, n.46, p.<33-49>,jan./jun. 2016 
tempo, um arrastado o-o-o-ó. Freud refere que este som representava a palavra alemã fort (partir). Após, puxava o carretel, expressando um alegre dá (ali), assim ele reaparecia. A mãe estava representada pelo carretel. Tratava-se de uma brincadeira completa, onde se evidenciava um desaparecimento e um retorno. Tratando-se do fort/da, podemos perceber que este vem a ser a falta que deixa na criança lugar para o significante, oferecendo espaço para as palavras. $\mathrm{O}$ fort/da é importante para a simbolização, é a partir do acesso ao simbólico que a criança passará a se constituir como sujeito.

Ainda, para a constituição de um sujeito separado e distinto em relação ao corpo e às palavras da mãe, é fundamental a entrada de uma terceira instância na relação mãe-bebê: a operação da função paterna. O que está em jogo é a entrada no social e na cultura e a função paterna é introduzida para o bebê, inicialmente, pela própria mãe; mas também precisa ser sustentada pelo pai e/ou pelos demais adultos que se ocupam da criança. De acordo com Bernardino (2006), para que se desenvolva o psiquismo, o organismo dotado de um aparelho biológico deve se articular às "pessoas que assegurem o cumprimento das funções paterna $e$ materna em suas acepções simbólicas" (p. 3).

A criança pede pela entrada de um terceiro, na relação dual. Willian pega livros em sua caixa de materiais e me oferece, o que interpreto como um pedido de leitura. Começo a leitura e Willian acompanha a história olhando para as figuras, e sem dar tempo que eu termine a leitura vai logo virando a página. Essa coleção de livros que Willian tem em sua caixa conta a história de animais ainda crianças, onde eles vivem, com quem vivem e o que comem. A história é contada pelo animal, ainda criança, em um segundo momento aparece outro personagem, da mesma raça, porém maior, e antes mesmo de eu ler quem é este personagem, Willian se entusiasma mais com a história e aponta rapidamente para este, o nomeando de "mamãe". Willian fica ansioso e vira a página com mais rapidez na esperança de encontrar um terceiro, que então encontra e o nomeia de "papai". A partir dele surge na história a figura materna e paterna, sendo este pai o terceiro, já entendido por Willian. 


\section{Sopa de letrinhas: a linguagem na constituição}

O uso da linguagem humana se diferencia das outras espécies por ser simbólica e gramatical. Além de expressivo, essa linguagem possui um papel constitutivo, ela pré existe à criança, muito antes de sua concepção, o bebê já é alguém de quem se fala, já há um desejo por parte da mãe por esse filho que virá a se constituir em um sujeito desejante. Para Lacan (195455/2009) o Outro como lugar da linguagem, lugar da fala, precede o sujeito, este é falado antes mesmo de seu nascimento. O sujeito é o ser constituído no campo do Outro. É nesse sentido que o sujeito não é uma substância. Ele é o efeito do significante. Ele é representado por um significante.

Se a constituição do sujeito se dá no campo do Outro, no acesso à linguagem, o Outro é

quem possibilitará que se dêem tais operações constituintes. É este Outro primordial que possibilita a entrada da criança na linguagem, por sua voz que responde e dá sentido ao choro e por seu gesto que toca e marca o corpo do bebê. Diante da ação da criança há uma interpretação do adulto, se há interpretação, há linguagem na cena, "mas é evidente que a linguagem não se inscreve por si. ” (JERUSALINSKY, 2011, p.110).

Freud como precursor da psicanálise deixou evidente que esta se dá através da cura pela fala, a expressão conhecida como talking cure. Onde o analisante fala o que lhe vem à cabeça, e por meio da associação livre obtém alguns direcionamentos de seu tratamento. Na infância o inconsciente está à flor da pele, sendo "escutado" pelo analista através do jogo, do brincar.

Quando a criança é pequena segundo Aimard (1986), é possível perceber uma linguagemprazer nos ruídos bucais, na sucção, nos jogos de balbucio. Na aquisição de linguagem, o balbucio é em parte imitação, auto-imitação, e o que importa mesmo é a significação e as características dessas produções.

A mãe opera na sonoridade pronunciada pelo filho e executa certos recortes e através destes, ela restitui o seu bebê como um ser da linguagem. Lacan (1954-55/2009) nos diz que uma "fala somente é fala à medida exata que alguém nela crê" (pg. 213). Para Cláudia, mãe de Willian, ele não é capaz de se comunicar, para seu pai Walmir, ele não fala por preguiça. Em suas brincadeiras nos atendimentos ele emite os sons e as expressões faciais dos personagens e eu entro dando uma voz para aquela brincadeira, falando pelos personagens e falando por Willian. 
Nesse momento há uma presença de ordem simbólica que, na medida em que ela for sustentada por um Outro Primordial, antecede o traço colocando-o na condição de signo e lhe outorgando sua posição significante (JERUSALINSKY, 2008).

Freud, em 1891, em seu estudo sobre as Afasias inaugurou uma concepção do psiquismo fundada na linguagem, já que apresenta o psiquismo como um aparelho de linguagem. A partir do estudo das afasias, ele busca entender os processos envolvidos nas atividades de falar e compreender. Para tanto, utiliza as noções de representação de objeto e de palavra ao propor a classificação das afasias em verbais, agnósticas e assimbólicas. Essas duas representações são complexos de associações compostas por impressões variadas que, ao se relacionarem, produzem sentido.

Grande parte das atividades da linguagem se situa na "zona transicional” do jogo, da ilusão da ficção. Na opinião de Aimard (1986) a palavra é o mais fiel, o mais universal e o mais manejável dos objetos transicionais. Nesse meio transicional, as formas sonoras emitidas, jogadas, reproduzidas, reenviadas de um a outro são como um jogo de espelho. Podemos vislumbrar isso em algumas sessões com Willian, onde brincamos de corrida de carro e estes se localizavam um ao lado do outro. Ele pegava dois carros dentre esses muitos e corria, elegendo um vencedor. A partir desse momento comecei a ser um juiz que fazia a contagem regressiva e permitia a corrida dando algumas instruções, como ter atenção, não falar ao celular durante a prova e alguns prêmios. De uma sessão para outra Willian começou a fazer o papel desse juiz falando alto, “aão, aão, aão ”, que eu interpretava como "atenção, atenção", e me olhava para obter um sinal de compreensão, ou permissão. O vínculo com a criança no atendimento em psicanálise nasce através de olhares, palavras, gestos, e por fim dá um dar sentido a este ser e ao seu viver.

Ao realizarmos uma lista de materiais que David precisava para sua caixa, sua fala era rápida, um tanto confusa, dificultando o entendimento. David misturava uma palavra na outra, uma fusão de palavras. Era preciso repetir o que se entendia, e após, ele confirmava ou não, me corrigindo se eu estivesse errada, e repetia um pouco mais calmo a palavra separada da frase. Com um diferente ritmo de sua fala, se fazia entender.

A partir de Lacan (1953/1998), só há um lugar possível para o sujeito: no significante que está no campo do Outro (mãe ou quem cumpre essa função). O bebê é um ser desamparado, que 
somente após o primeiro movimento em direção ao Outro, como lugar do significante, é que o sujeito se torna algo. Dessa maneira, há uma dependência do ser falante em relação à linguagem.

A palavra dada ao bebê é vinda da mãe, de acordo com Bergés e Balbo (1997) a mãe significa as ações do bebê, ao mamar, ao sugar. A partir de Winnicott (2006), além da mãe significar essas ações, ela precisa participar e suportar. Jerusalinsky (2010) complementa essa significação, defendendo que a linguagem da criança já está nas primeiras emissões sonoras, no jogo de presença e ausência apelando para recuperar a mãe frente à desaparição real dela. A palavra significada é o que ocorre com os casos clínicos de David e Willian, onde, enquanto terapeuta vou dando voz significada a eles. Essa questão da presença e ausência pode-se perceber no caso de David quando há intervalos ao me afastar da sala.

A criança pode ser ouvida para além de seu dizer, para Lacan (1953/1998), devemos supor algo na criança, supor em seu fazer, pois para ela há um motivo pelo qual está fantasiando, desenhando. Há um Outro dando sentido às ações da criança, decodificando sua mensagem. Para Laznik Penot (1997) os sons se tornam mensagem para um terceiro que assim os recebe e isso produz efeitos à posteriori sobre a própria criança. Ela pode, então, se reconhecer como agente desta mensagem.

Piaget (1987) afirma que o conhecimento e a linguagem são o resultado de trocas entre o organismo e o meio, havendo sempre um fator endógeno, orgânico, que antecede a construção do conhecimento e da linguagem. Aimard (1986) faz uma crítica à teoria de Piaget, pois a linguagem para ele é a da razão, não esclarecendo a linguagem da relação; assim como o tempo e o espaço "são construções racionais que ignoram a dimensão que fornecem o vivido e as variáveis que introduzem as experiências relacionais precoces”. (p.27)

Saussure (1916/2000) reconhece assim que o fato fonatório não começa nem na ordem acústica e nem na ordem fisiológica, "mas representa um equilíbrio entre as duas, constituindo uma ordem própria, que pede suas próprias leis e suas próprias unidades” (p. 213). Dessa maneira, Saussure (1916/2000) defende que não é a linguagem que é natural do homem, mas a faculdade de construir uma língua. Essa faculdade desempenha o principal papel na organização do sistema, por que está ligada aos princípios de associação e de coordenação. 


\section{Brincando a gente se entende}

Dolto (1996) expõe que para que a criança possa falar é necessário que quando se fale com ela se utilize da atenção, do olhar e as mímicas, pois por sua vez a criança procura o contato, quer que a compreendam. A criança arrisca as primeiras palavras por meio do brinquedo e introduzindo-se na conversa de outros, como o pai e a mãe. Para Jerusalinsky (2010) a mímica e o gesto se instalam como funcionamento básico da linguagem, a linguagem já está ali, mas a criança é que deve descobri-la e se apropriar dela em uma trama significante. Dessa maneira, se percebe que a linguagem está no corpo.

O universo do brincar é essencial para a criança na construção de seus significantes. Rodulfo (1990) expõe que este é o método mais eficiente para avaliar o desenvolvimento simbólico de uma criança, e irá fornecer de maneira clara o estado de suas possibilidades. Neste contexto, identificamos que o brincar e a fala andam juntos e que são fundamentais para a constituição e subjetivação da criança. O brincar, segundo Flesler (2008) implica a passagem do Real ao Simbólico. O lugar do brinquedo e do jogo como promotores do texto são elementos essenciais para a fala, constituindo lugares fundamentais para a entrada do sujeito na linguagem.

Nas sessões com David não podia faltar massinha de modelar e a tesoura. David utiliza das massinhas para fazer comidinha, bolos, enrolando em um formato de cobra e as corta em pedaços. Em um atendimento sugeri que fotografássemos uma de suas construções, ele pediu então que queria muito levá-la embora. Permiti. Construiu uma flor, pétala por pétala, caule e folha. Fotografamos. Nos segundos posteriores David amassou por completo a for, transformando- a em um monte de massinha de modelar. O que David queria mesmo era a massinha de modelar, e não a sua construção sobre ela. Ao misturar as massinhas, as confunde assim como suas palavras. Isso fala sobre um tempo em que David não consegue se construir, dar vazão as palavras e um contorno sobre elas.

Certa vez entramos na sala de atendimento com uma caixa cheia de panelinhas, mas ao nos acomodarmos para prosseguir o atendimento, David deu falta da massinha de modelar e da tesoura. Ficou decepcionado e disse: "não vai dar pra gente brincar hoje, por que não tem massinha, tem que buscar”. Perguntei a ele, se não poderíamos fazer com outra coisa o que faríamos com a massinha, e ele foi resistente dizendo que não: -“Comidinha tem que ser feita de 
massinha". Sugeri então fazermos comida de papel picado, David desconfiou de como ficaria, mas aceitou. Em cada panela tinha algo diferente: massa, coxa de galinha e arroz. Recortei a folha no formato de coxa de galinha, enquanto ele recortava o arroz e juntos fizemos a massa. David se surpreendeu com o resultado, e entusiasmado brincou a sessão toda. No fim desta, encontrou um pote transparente dentre as panelinhas e sem restrição misturou a variedade de "alimentos".

Mais uma vez a mistura se faz presente na vida de David, a fusão se reproduz na brincadeira. Algo que precisa ser dividido, algo que precisa ser cortado, dando-lhe o suporte necessário para sua constituição. No inicio do atendimento de David sua fala era muito pobre, ninguém o entendia verbalmente, da mesma maneira que seus irmãos. Era como se falassem um dialeto fraternal.

Talvez os momentos de reunir a família ocorram nos momentos de compartilhar o alimento, e por isso David brinca muito com isso, pois, a criança brinca, também, com a sua realidade. Rodulfo (2008) recorre a Winnicot para pensar sobre o brincar, e este é indiferente ao verbal/não verbal, ou seja, um som dentro da boca é tão brinquedo quanto o móbile colorido, o carrinho ou a boneca. Conseqüentemente, "uma criança suporta, em seu brincar, o que o dizer ainda não pode falar" (JERUSALINSKY, 2010, p.49).

De acordo com Rodulfo (1990) o brincar possui uma função essencial, onde a criança vai se curando por sim mesma. Ao longo do processo de estruturação e na medida dela o brincar vai se ressignificando. Quando Willian inicia seus atendimentos, os sons de lutas se fazem presente, o que se transforma com o tempo, passando para a presença da dupla lutando, e após brincando de cabra- cega, onde um tem que achar o outro, e ainda por meio da tinta pintar as mãos e produzir uma marca no papel. A marca no papel de nossas mãos foi tão interessante que se prolongou para a marca da mão dele com tinta branca na minha mão pintada de preto. Quando isso ocorreu seu rosto foi tomado de grande alegria e eu exclamei: "Willian, deixaste uma marca em mim, estamos de mãos dadas". Não há necessidade de pegá-lo no colo como sua mãe fazia, e sim andar lado a lado. Há muitas interpretações sobre esse "não falar" de Willian, pensando nisso resgato as marcas que ele pode nos deixar, mesmo que não seja através da expressão oral.

No brincar é possível visualizar meios das crianças se expressarem, e estes meios aparecem nos tempos da criança. Rodulfo (2008) associa o corpo materno como um objeto de 
brinquedo do bebê, onde ao mamar e sugar o seio, já brinca com este e com os objetos ao seu redor. Quando bebês, ninguém nos ensina a agarrar e puxar uma mecha de cabelo nem a transformar uma colher num instrumento de percussão, é quase instinto. “O corpo do Outro é a jazida por excelência", a criança mexe em qualquer orifício deste, boca, nariz, orelha, cabelo, e puxar qualquer objeto à vista neste corpo, brincos, colares, botões, roupas, e ao crescer suas habilidades, a criança busca neste corpo o qual ela vive, significantes que a constitui (RODULFO, 1990).

O corpo e o espaço andam juntos, sendo coisas diferentes. Em um atendimento David tranca a porta da sala conosco dentro, e então começo a perguntar como sairíamos dali. Ele sugeriu muitas soluções, mas todas utilizando a janela e não sugeriu o óbvio, que seria deschavear a porta. O faz- de -conta é importante para entrar na fantasia, no mundo imaginário. A partir de Dolto (1996), a criança necessita das fantasias de domínio de sua vida e sua morte, é por meio destas brincadeiras que a criança suporta, a realidade da restrição a liberdade, imposta à todos pela natureza das coisas, pelo sofrimento e pelas leis sociais. O imaginário serve para se defender do drama da realidade. "A imaginação (fantasia) e poesia infantis, não são nem de credulidade nem puerilidade, e sim, uma inteligência em uma outra dimensão" (DOLTO, 1996).

\section{Brincando com palavras}

É como se no trabalho clínico com crianças, acolhêssemos os seus sintomas, viabilizando a construção de novos contornos, soprando o texto de sua própria história, na busca de um endereçamento possível situado no plano simbólico.

A construção, a leitura dava a possibilidade de existência para além da história do não falar. O espaço do atendimento clínico como um espaço de subjetivação, não se trata de realidades dadas, mas produzidas pelo próprio sujeito na tentativa de se produzir.

Jerusalinsky (2008) traz que para Lacan é esse o ponto onde podemos chegar além da palavra, na medida em que a psicanálise entra no campo da linguagem pela via da fala. Sendo a fala o objeto de uma escuta, a Psicanálise entra nas questões da língua, do discurso e da linguagem. 
Em cenas anteriormente citadas é possível perceber que nos casos de Willian e David há algo de uma antecipação, uma antecipação de tempo. Segundo Aimard (1986), na medida em que o bebê estabelece relações entre os comportamentos e suas consequências, ele se torna capaz de antecipação: ele prevê consequências comportamentais, apela, estende os braços, sabendo qual é a resposta habitual do adulto.

Isso me recorda uma sessão em que Willian brincava com um carrinho, ele ia de um lado a outro da sala e por vezes batia um carrinho contra o outro, estava tão mergulhado em sua brincadeira que demorou a perceber que eu o olhava. Quando me percebe, me indaga “o quê?”. Willian me perguntava o que estava fazendo de errado, minha expressão facial era normal, mas ele achou que eu o repreenderia. Disse-lhe que estava com vontade de brincar com ele, o que logo ele aceitou me alcançando um carrinho. Nesse momento há algo de uma antecipação de Willian, com receio que eu o repreenda, diga-lhe para se comportar ou parar de bater um carrinho contra o outro, o que geralmente ocorre na família e na escola. Surpreende-se com a minha reação e me autoriza a brincar com ele.

Para a constituição de uma linguagem, é de extrema importância, a partir de Quadros e Finger (2008), a noção de tempo (passado, presente e futuro). Para Piaget (1987), a distribuição no espaço um antes, agora e depois antecedem a noção de tempo, dessa maneira a criança adquirirá a noção de tempo depois da noção de espaço. Nesses casos os significantes tempo e espaço se dão através da antecipação, onde Willian vira a página do livro antes mesmo do término da leitura, e David fala de maneira rápida e confusa, colocando palavras em cima de palavras.

$\mathrm{Na}$ análise de crianças é possível ler o que está escrito por meio do brincar. Bernardino (2008) diz que é neste momento que é possível transformar as angústias em palavras, em desenhos e em brincadeiras, em busca de significações. "É possível analisar uma criança que brinque sem falar como é impossível analisar uma que fale sem brincar” (RODULFO, 2008).

Dolto e Nasio (1991) identificam o trabalho analítico com crianças como uma confrontação de lugares, ritmos e imagens do corpo. É a partir desse meio que o analista opera envolvendo suas próprias imagens de corpo com as imagens do corpo da criança. É de extrema importância falar verdadeiro com a criança, considerando que esta é inteiramente "linguagem em seu ser", e compreende tudo o que lhe dizemos. 
A partir disso, Saussure (1916/2000) concebe a relação da criança com a língua como aprendizagem, que se dá a partir das suas experiências linguísticas com os indivíduos de sua comunidade linguística, ou seja, "as impressões recebidas ao ouvir os outros que modificam seus hábitos linguísticos" (pg. 27).

$\mathrm{Na}$ análise o fazer da criança e o deixar-se fazer do analista são os dois fatores que orientam a escuta dos traços eu recortam o objeto que a criança se faz para o Outro (WANTAL, 1988). Quando o terapeuta brinca com a criança, ele já está formando uma relação, um elo, uma transferência. Nas lutas com Willian, assim como os bonecos eram uma extensão de seu corpo. Ele era uma extensão do meu corpo também, ou até quando utilizávamos nos nossos próprios corpos , assim como, na brincadeira com tinta, onde essa tinta marcava um ao outro. Ao criar suas produções com a massinha, David solicitava a minha ajuda nem que fosse para lhe alcançar algo, como uma auxiliar.

Para Jerusalinsky (2008),

Ao mesmo tempo, por meio das descontinuidades, das substituições, da variabilidade, da proposição de representações não representacionais, e da repetição de diferenças, o filhote é introduzido na função simbólica. O curioso é comprovar que é por meio destas inconstâncias que a persistência materna captura o bebe na condição de sujeito de uma língua: evidentemente uma que resguarda, em oposição dialética com a língua de todos, aposição narcisista do pequeno sujeito ali suposto. É por isso que podemos considerar que a entrada da pequena criança na linguagem se faz muito mais pela concordância das representações com uma gramatica inata. (pg.158).

Segundo Aimard (1986) o desenvolvimento da palavra se inscreve no tempo. A linguagem como objeto de troca, de diálogo, com a mãe e com os outros, é uma parte de si mesma que a criança "doa ou retém, deixa transbordar ou controla parcimoniosamente". A palavra é também a do outro, doce, apaziguadora como ninar, mas é também a das proibições, dos limites, dos "nãos”.

No atendimento de crianças pequenas e com grandes dificuldades é necessário fazer o papel de Outro, onde este outro possa ressignificar o seu dizer. Nos atendimentos com Willian e David sinto que é o que ocorre aonde estes vão se estruturando simbolicamente e dando conta de suas questões. 


\section{Concluindo}

O trabalho clínico com crianças possui dificuldades e impasses tanto quanto a clínica com adultos, porém as crianças falam de seus sintomas de muitas maneiras, e muitas delas envolvem seus pais. E, quanto aquelas que "não falam” ou "não se fazem entender"? A clínica psicanalítica oferece um espaço de construção, e é a partir dessa construção que será possível ler e questionar de que lugar o paciente fala e a quem ele se remete.

Este escrito percorre um conjunto de reflexões a partir de leituras e da prática clínica sobre a relação mãe-bebê. Destaca-se o fato de que ambos os casos das crianças compartilhados aqui têm seis anos de idade. Essa relação dual é primordial para o desenvolvimento infantil, um desenvolvimento psíquico e motor. A nossa suspeita é que essa inscrição de palavras, inscrição de uma marca no corpo, foi dada de maneira tardia, ou melhor, ainda está sendo dada.

Após um fim de semana, Cláudia, mãe de Willian, comenta no fim do atendimento que ele tem adorado "ler" gibis, ainda mais da turma da Mônica. É dessa maneira que percebemos que Cláudia conseguiu supor que seu filho lê, que há palavras em seu viver. Presenciando este momento, Willian se despede de mim, e descendo já as escadas me fala em um tom mais alto: "te amo tia". Percebe-se que a transferência já está estabelecida, esse laço transferencial pode

promover um trabalho mais significativo. Acredito que o que ele estava amando naquele momento, era sua mãe por ter significado o seu olhar em cima das figuras dos gibis. Por que para "ler" precisamos "olhar" e "escutar".

$\mathrm{Na}$ escola Willian batia nos colegas e depois chorava, foi esta a maneira que encontrou para se comunicar, e dizer o quanto é difícil fazer com que os outros o entendam e brinquem com ele. A linguagem da criança vem de maneira saudável, quando ela tem algo a dizer (DOLTO, 1996).

Já David encontrou maneiras de organizar suas palavras brincando. Ele traz melodias e músicas que aprendera na escola, expõe seu desejo de além de cantá-las, escrevê-las, comprovando que ali no papel há algo inscrito, algo dele. O cuidado que David tem tido com seus materiais é surpreendente. Certa vez, no fim de uma sessão anunciou que na sessão seguinte organizaria sua caixa que estava uma "bagunça". E assim o fez. Com cuidado tirou todo seu 
material da caixa, limpou, e os devolveu a ela de outra maneira. Assim, David consegue "limpar" suas frases, "incrementar" suas brincadeiras e dar sentido aos seus atendimentos.

Por meio deste texto foi possível perceber que as primeiras vocalizações da criança sendo significadas por um outro - representante da língua - são colocadas em uma série significante o que possibilita que venham a se transformar em fala. Ao ser reconhecida como falante, mesmo que ainda não fale, a criança inicia um processo de apropriação da língua, instância decisiva para o seu desenvolvimento global e para a sua estruturação psíquica. A linguagem inicia desta suposição/ investimento libidinal e aos poucos, a palavra se destaca do contexto imediato de sua produção e adquire caráter cada vez mais simbólico e representativo.

A interlocução entre o brincar e a linguagem é de extrema importância na psicanálise infantil, pois assim é possível uma escuta cada vez mais aguçada sob a criança em questão. Ao emprestar significantes à uma criança em atendimento estamos inscrevendo nesta, nosso desejo que ela não sofra com seus problemas, mas sim, saiba conduzi-los. Dessa maneira, a transferência se torna necessária para que a tomada de significantes se dê, e fazendo com que a criança realmente tenha possibilidades.

\section{Notas:}

(1) "Fala ser" é um neologismo de Lacan, que também Alfredo Jerusalinsky (2008) utiliza para identificar a polissemia operada entre fala e falo.

(2) Nome Fictício

(3) Nome Fictício

\section{TO PLAY AND THE LANGUAGE: AN INTERFACE NECESSARY TO A PSYCHOANALYTIC CLINIC}

\section{Abstract}

This work is mainly focused on the play and the language in children clinical care and their importance to the individual psychological constitution. To work the language and the play in Psychoanalysis and verify their mutual influences, we used two clinical cases. We divided the 
work into four topics: born a "human speech"; little letters sup: the constitution on the language; we understand each other playing; playing with words. The playing and the language are essential to build significant in childhood. Gradually the word stands out from the immediate context of the need to be named and acquires character increasingly symbolic and representative. When we lend significant to a child in clinical care we are signing on this, our hope that they do not suffer with their problems, but rather learn to lead them and become a desiring individual. This work is of great relevance to a heightened listening and a more sensitive looking to the childhood psychoanalytic clinic.

Key-words: to play; language, psychoanalysis clinic.

\section{Referências}

AIMARD. Paule. A linguagem da criança. Tradução: Franscisco Vidal. Porto Alegre: Artes Médicas, 1986.

BERGÉS, Jean; BALBO, Gabriel. A criança e a psicanálise: novas perspectivas. Tradução Francisco Franke Settineri. Porto Alegre: Artes Médicas, 1997.

BERNARDINO, Leda M. F. A abordagem psicanalítica do desenvolvimento infantil e suas vicissitudes. In: Bernardino, Leda (Org). O que a psicanálise pode ensinar sobre a criança: sujeito em constituição, pp. 19-41. São Paulo: Escuta, 2006.

BERNARDINO, Leda. M. F. Angústia na clínica psicanalítica com bebês e seus pais. Revista da Associação Psicanalítica de Porto Alegre, Porto Alegre, 2008. n. 35, p. 21-29.

DOLTO, Françoise. Quando surge a criança. Tradução: Marina Appenzeller. Campinas, SP: Papirus. 1996.

DOLTO, Françoise; NASIO, Juan D. A criança do espelho. Porto Alegre, Artes Médicas, 1991.

FLESLER, Alba. Os tempos do sujeito. Revista da Associação Psicanalítica de Porto Alegre. Porto Alegre, 2008. n. 35, p. 178-192.

FREUD, Sigmund (1920). Além do princípio do prazer. In: Edição Standart Brasileira das Obras Psicológicas Completas de Sigmund Freud. Rio de Janeiro: Imago, 1996.

FREUD, Sigmund (1891). Sobre a interpretação das Afasias. In: Edição Standart Brasileira das Obras Psicológicas Completas de Sigmund Freud. Rio de Janeiro: Imago, 1996.

JERUSALINSKY, Alfredo. Saber Falar: Como se adquire a linguagem? Petrópolis: Vozes, 2008. 
JERUSALINSKY, Alfredo. Psicanálise e desenvolvimento infantil: um enfoque transdisciplinar. Tradução: Diana Myriam Lichtenstein. 5a ed. Porto Alegre: Artes e Ofícios, 2010.

JERUSALINSKY, Julieta. A criação da criança: brincar, gozo e fala entre a mãe e o bebê. Salvador, BA: Ágalma, 2011.

KUPFER, Maria C. M. Notas sobre o diagnóstico diferencial da psicose e do autismo na infância. Revista Psicologia USP. São Paulo: 2011. 11(1), pg. 85-106.

LACAN, Jacques (1953-54). O Seminário. Livro 1: os escritos técnicos de Freud, $2^{\mathrm{a}}$ ed. Rio de Janeiro: Jorge Zahar Editor, 2009.

LACAN, Jacques (1953). Função e Campo da Fala e da Linguagem em Psicanálise. In: Escritos. Rio de Janeiro: Jorge Zahar Editor, 1998.

LACAN, Jacques (1954-1955). O Seminário, Livro 2. O eu na teoria de Freud e na técnica da psicanálise. Rio de Janeiro: Jorge Zahar Editor, 2009.

LAZNIK- PENOT, Marie- Cristine. Rumo à palavra: três crianças autistas em psicanálise. Tradução Mônica Seincman. São Paulo: Editora Escuta, 1997.

PESARO, Maria E. Alcance e limites teórico-metodológicos da pesquisa multicêntrica de indicadores clínicos de risco para o desenvolvimento infantil. Tese de Doutorado, Universidade de São Paulo, 20010.

PIAGET, Jean. O nascimento da inteligência na criança. Rio de Janeiro: Guanabara, 1987.

QUADROS, Ronice M.; FINGER, Ingrid. Teorias de aquisição da linguagem. Florianópolis, Ed. da UFSC, 2008.

RODULFO, Ricardo. O brincar e o significante: um estudo psicanalítico sobre a constituição precoce. Trad: Francisco Franke Settineri. Porto Alegre: Artes Médicas, 1990.

RODULFO, Ricardo. Encontros: Sonata para psicanálise a várias vozes. Revista da Associação Psicanalítica de Porto Alegre. Porto Alegre, 2008. n. 35, p. 110-125, jul./dez.

SAUSSURE, Ferdinand de. (1916). Escritos de linguística geral. Organizados e editados por Bouquet, S. e Engler, R. São Paulo: Cultrix, 2000.

WINNICOT, Donald. Os bebês e suas mães. Tradução: Jefferson Luiz Camargo. $3^{\mathrm{a}}$ edição. São Paulo: Martins Fontes, 2006.

Data de recebimento: $15 / 12 / 2014$

Data de aceite: $23 / 03 / 2017$ 


\section{Sobre os autores:}

Iassana Scariot é psicóloga, Psicanalista, graduada pelo Centro Universitário FranciscanoUNIFRA; Especialista em Atendimento Clínico pela Universidade Federal do Rio Grande do Sul- UFRGS. Endereço Eletrônico: iassana.scariot@gmail.com

Liliane Seide Froemming é psicóloga, Mestre em Psicologia Clínica pela UNB, Doutora em Psicologia UFRGS, Analista membro da Associação Psicanalítica de Porto Alegre. Professor associado da UFRGS. Endereço Eletrônico: lilifrom@portoweb.com.br 